\title{
Análisis morfoestructural de la arquitectura defensiva en el ámbito indígena y colonial de la protohistoria antigua peninsular (ca. $1000-600$ A.C.)
}

\author{
Víctor RODERO OLIVARES \\ Luis BERROCAL-RANGEL \\ Universidad Autónoma de Madrid (UAM)
}

\section{Resumen}

Este artículo presenta un avance de los resultados de nuestras investigaciones ${ }^{1}$ sobre el poblamiento amurallado en el cuadrante suroccidental de la Península Ibérica en el tránsito del II al I milenio antes de nuestra era. Los sistemas defensivos se configuran no sólo como un reflejo de las complejidades y vicisitudes socioeconómicas de una población sino también en un referente simbólico comunitario en el que se vuelcan las técnicas edilicias más novedosas. A este respecto el estudio de la Arquitectura defensiva protohistórica constituye un "artefacto" con el que poder dilucidar de modo indirecto patrones y pautas de interacción social.

Palabras clave: Fortificaciones, Bronce Final, Edad del Hierro, poblamiento, muralla.

\section{Summary}

This paper shows a preview from our investigations on fortified settlement in the Southwestern Iberian Peninsula at the end of the Final Bronze Age and the beginnings of the Early Iron Age (X-VII cent. B.C.). In this context defensive architecture works as an useful tool for archaeologists looking for socio-economic changes and symbolic communal signs so its uses to incorporate quickly new techniques but also adapt them to theirs owns customs and singular environments.

Keywords: Fortifications, Final Bronze, Iron Age, settlement, rampart.

1 En 1994 uno de nosotros publicó un primer estudio sobre la Poliorcética antigua en Europa en el, por entonces, prestigioso medio de difusión que era la Revista de Arqueología. Dicho trabajo, pionero por entonces en el panorama peninsular, antecedió a nuevas publicaciones sobre el tema, incluyendo monográficos como el que recoge las actas del coloquio "Paisajes fortificados de la Edad del Hierro" que coordinamos en 2006 junto al Dr. Pierre Moret dentro del proyecto de I+D+I Las murallas protohistóricas de la Península Ibérica (BHA 2003-02199). Fruto de la misma línea de investigación fue el proyecto internacional de excavaciones "Castro dos Ratinhos, Moura-Alqueva, Portugal", cuya parte española fue dirigida por los autores de este trabajo y cuyos resultados se exponen en una reciente monografía publicada por el Museu Nacional José Leite do Vasconcelos de Lisboa en 2010. Todos estos resultados parten del interés suscitado en nosotros por una de esas clases magistrales que caracterizaron la labor docente del profesor Manuel Bendala, Tuvimos la fortuna de recibirla años antes durante los estudios de licenciatura, con el entusiasmo de quien siempre tuvo una predilección especial por la poliorcética antigua, y por la helénica en particular. A él queremos dedicar con toda nuestra gratitud estas líneas. 


\section{INTRODUCCIÓN}

A inicios del I Milenio A.C., la aventura comercial fenicia se constituyó en una estrategia expansionista polifacética que transformó desde una óptica estructuralista las comunidades peninsulares. Su presencia condujo a la aculturación de las sociedades del Bronce, definida como un proceso de transformación y de cambio cultural basado en la adopción y adaptación de pautas y patrones de raigambre oriental (Aubet, 2009; Celestino et alii, 2008; Díes Cusí, 2001; Wagner, 1995 y 2003). De este modo, se imprimió un nuevo desarrollo en la evolución histórica de las poblaciones indígenas, incentivando y originando nuevas dinámicas socioeconómicas, sociales, ideológicas y políticas.

No obstante esta complejidad cultural debería ser comprendida dentro de un proceso endógeno previo a la colonización fenicia, cuyos inicios deben situarse en el tránsito del II milenio al I milenio A.C., que se desencadena en ciertas áreas peninsulares y tiene su reflejo en el registro arqueológico. Durante el Bronce Final II-III se agudizó esta dinámica que convergió a principios del primer milenio a.C. con la presencia colonial (Celestino et alii, 2008). Nuevas relaciones sociales y de poder se entremezclaron con las redes tradicionales existentes de tipo comunal o local. De este modo, a principios del milenio, las poblaciones locales experimentaron una jerarquización cada vez mayor, que en términos holísticos, se define como sociedad estratificada (Kristiansen, 1998, 75-77; Almagro-Gorbea, 1998).

A propósito de la colonización fenicia, ésta debe entenderse como un reflejo en directa relación con el desarrollo de una empresa comercial que se materializa en unos nuevos marcos poblacionales y nuevas relaciones socioeconómicas de interacción. En este sentido, el registro arqueológico constata cómo grupos de población fenicia se asentaron gradualmente, pero en un breve período de tiempo, en el litoral peninsular. La presencia colonial semita y sus redes comerciales afectaron no sólo a las zonas limítrofes con sus establecimientos comerciales, la zona onubense, Bajo Guadalquivir y la costa malagueña, sino que alcanzaron desde el siglo VIII A.C., e incluso antes, la costa mediterránea y el litoral atlántico portugués, si bien los recientes descubrimientos e investigaciones en Arqueología confirman que estas fechas deben rebajarse hasta el siglo IX A.C. e incluso las postrimerías de la centuria anterior (Soares y Martins, 2010; Serrano, Llompart y González de Canales, 2004). La llegada de los colonos orientales supuso un proceso de interacción cultural con las sociedades indígenas, que a su vez, conllevó el cambio cultural de éstas.

Dicho cambio se manifestó al mismo tiempo en una jerarquización basada en la concentración y apropiación de los recursos y en la redistribución de los mismos por parte de las elites dirigentes, que van a acumular riqueza y símbolos de prestigio en los intercambios con las poblaciones fenicias.

La llegada colonial oriental, indudablemente, debió suponer un elemento clave en la construcción del paisaje protohistórico conformando una articulación urbana y definiendo un paisaje humanizado a partir de las pautas y patrones previos de las colonias fenicias en Occidente (Helas y Marzoli, 2009; Riva y Vella, 2006; Acquaro y Ferrari, 2004; Costa y Fernández, 2002;Gras, Rouillard y Teixido, 2000; Aubet, 1994...). Así mismo el establecimiento de comunidades semitas en la Península Ibérica condujo a una rápida incorporación de novedades tecnológicas en las sociedades indígenas. Estos cambios se materializaron tanto en la arquitectura civil como militar de una forma técnica y formal. La aceptación de estas novedades técnicas, aisladas o en conjuntos, facilitó la asimilación de los nuevos modelos importados desde el Levante mediterráneo, no sin aplicar los cambios adaptivos impuestos por las tradiciones o los ecosistemas peninsulares (Vives-Ferrándis, 2005; Prados 2003; Dies Cusí, 2001...)

Sea como fuere, esta evolución hacia una mayor segmentación social, pero también hacia una concentración de poder y una centralización y apropiación de los recursos económicos por parte de las elites dirigentes, tendrá su reflejo en el papel cada vez más destacado que proporcionó el control territorial, la articulación de los sistemas de poblamiento y la aparición de núcleos rectores, con sistemas defensivos cuya importancia radica en configurarse como vértices del tejido espacial y social, como ejes de un proceso de humaniza- 
ción del paisaje cada vez más creciente y acelerado en la protohistoria peninsular (p.e., en: Bendala Galán, 2000, 107ss.).

El papel de los asentamientos fortificados ejerce no sólo una funcionalidad práctica. Más allá de la finalidad pragmática de las defensas protohistóricas como elementos fácticos de defensa, estas construcciones fueron manifestaciones explícitas de la nueva concepción social e ideológica traída por los colonizadores (Prados y Blánquez, 2007, 64ss). El análisis de las fortificaciones pre y protohistóricas en la historiografía arqueológica ha sido abundante y prolífico en las últimos años (Berrocal-Rangel y Moret, eds. 2007; Oliver Foix, ed. 2006...). Más allá de enfoques descriptivos, la Arqueología actual ha intentado discernir su valor integral, trascendiendo del carácter físico-funcional como única justificación de su presencia (Berrocal-Rangel, 2004). Dejando, un tanto, a un lado el incuestionable carácter militar, en las últimas décadas el panorama científico ha identificado que el significado de una muralla adquiere cada vez más tintes polivalentes. En este sentido, se ha experimentado un auge de las investigaciones centradas en los diversos matices de la interpretación de la edilicia defensiva desviando su interés en cuestiones simbólicas, sociales o culturales (Blánquez, 2008; Berrocal-Rangel y Moret, 2007; Escacena, 2002).

\section{EL BRONCE FINAL: UN "ENGRANAJE EN el CírCulo de Comercio atlántico.}

A finales del II milenio el registro arqueológico apunta a que la Península se sitúa integrada en las vías de intercambio comercial que se intensifican en esos momentos y que conectaron la fachada atlántica europea, incluyendo el litoral mediterráneo peninsular, con los circuitos comerciales del Mediterráneo central (Celestino et alii 2008; Kristiansen y Larson, 2006; Harrison 2004; Ruiz-Gálvez 1998; Coffyn $1985 \ldots)$.

Dos áreas, la zona onubense y el eje del Bajo Guadiana, son llamativas en lo que respecta a la evidencia del registro arqueológico sobre los recintos amurallados de este momento, pese a que la emergencia de centros fortificados a fina- les del II milenio no se circunscribe sólo a estas regiones. El mismo fenómeno se observa también en otras zonas peninsulares en momentos previos a la colonización fenicia, como en el hinterland malagueño, en las Beiras y Alto Alentejo portugueses o la cuenca media del Guadiana (García Alfonso, 2007, 378-380; Rodríguez Díaz y Enriquez, 2001; Calado, Barradas y Mataloto, 1999).

Las investigaciones arqueológicas en el área onubense han evidenciado un patrón de ocupación cada vez más amplio que abarcaba desde el litoral atlántico con la ciudad de Huelva hasta las estribaciones de los Picos de Aroche y Sierra Morena, pasando por la Tierra Llana (Fig.: 1).

En Niebla [ $\left.n^{\circ} 1\right]$, los trabajos en la década de los 90 y principios de este siglo en la cerca islámica en la Puerta de Sevilla y la del Desembarcadero han sacado a la luz una superposición estratigráfica de los distintos muros defensivos del asentamiento (Bedia y Borja, 1992; Bedia y Pérez Macías, 1993; Pérez Macías, Campos y Gómez Toscano, 2000). En una etapa previa al impacto colonial, Niebla se habría dotado ya de una estructura defensiva compuesta de una muralla de mampostería con un paramento exterior en talud así como de bastiones o torres de planta semicircular distribuidas a intervalos irregulares. A esta fortificación le sucederá tras un hiato temporal, otra cerca defensiva de características arquitectónicas bien distintas y fechada ya en el período Orientalizante (Campos, Gómez Toscano y Pérez Macías, 2006).

Al interior, en el territorio en torno a Aznalcóllar (Sevilla) [ $\mathrm{n}^{\circ}$ 2] se conocen dos yacimientos protohistóricos - Los Castrejones y el Castillo - separados por un curso fluvial y distante entre sí por medio kilómetro. En 1995 en Los Castrejones se realizaron unos sondeos que tenían como objetivo principal la delimitación espacial del yacimiento. En el corte 4 se localizó un lienzo de muralla compuesto por un muro en talud sobre el que se situaba un paramento recto. Así mismo, en la acrópolis se documentó un recinto defensivo en talud (Hunt, $1995 ; 2003)$. A esta estructura se le adosó posteriormente por la cara externa una torre maciza de planta cuadrangular. 

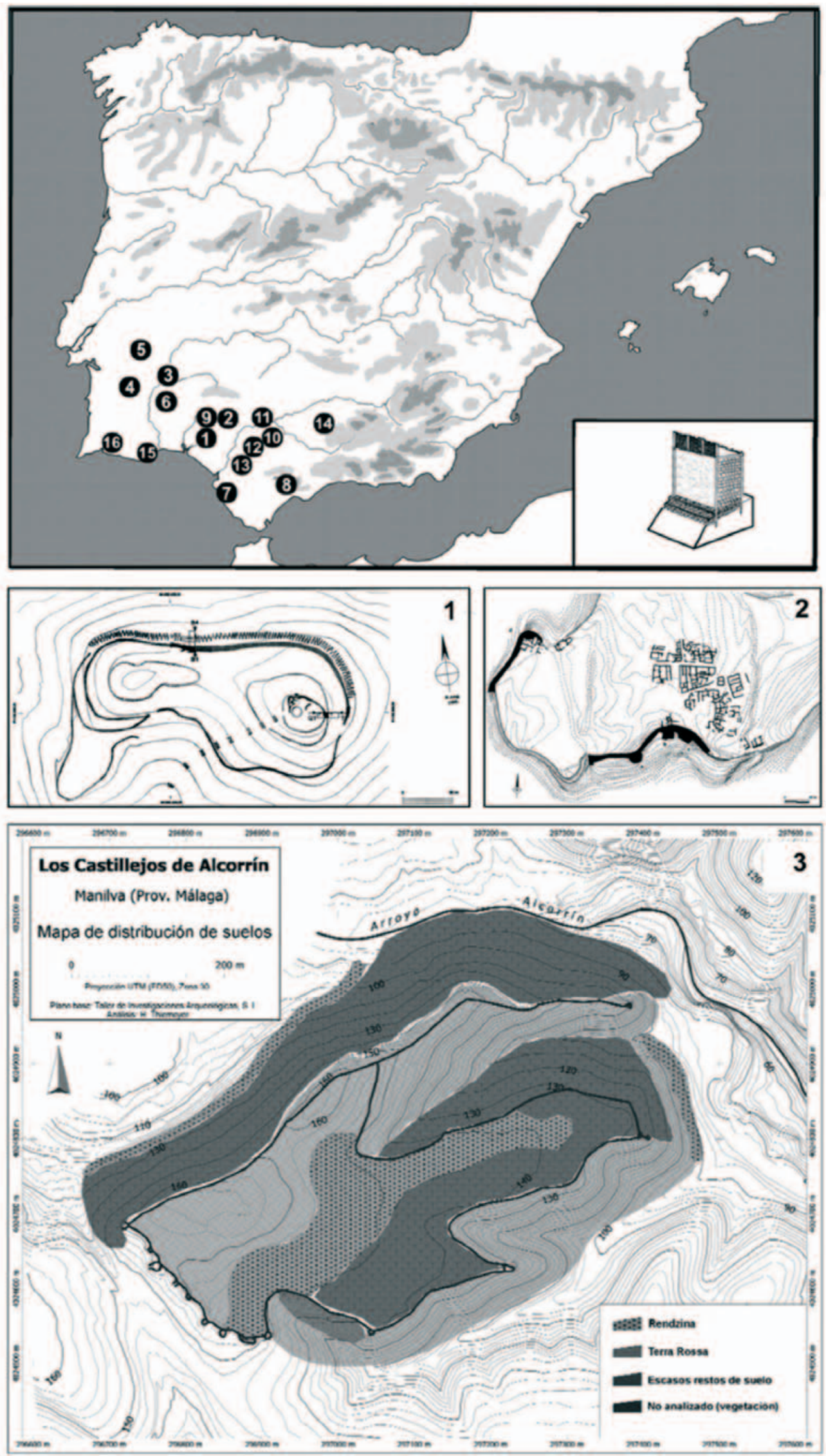

Figura 1: Localización de los yacimientos estudiados y numeración según el texto; 1. Plano de Ratinhos [nº 3], Moura (según Berrocal y Silva 2010); 2. Tejada la Vieja, Huelva [no 9] (según Fernández Jurado 1987); 3. Los Castillejos de Alcorrín, Málaga [no 8] (según Marzoli et alii 2009), todos a la misma escala. 
Ambas obras se levantaron a partir de muros paralelos que dejaban un espacio intermedio que fue rellenado con barro y piedras más pequeñas (Hunt, 1995, 509-510).

En el asentamiento de Huelva, a pesar de no haberse localizado ninguna construcción defensiva, se ha planteado su existencia a partir de su importancia en las redes locales y en las posteriores relaciones con los fenicios, así como por el análisis de la deposición de los sedimentos y el muro del Cabezo de San Pedro (Gómez Toscano, 2006, 36-38), ampliados por los espectaculares materiales procedentes de la plaza de las Monjas, en Huelva (González de Canales et alii 2004).

Estos núcleos fortificados se articularían en una red dirigida a la explotación de los recursos metalíferos y minerales de la zona. A su vez, entorno a estos centros hegemónicos se localizarían poblados en llano con estructuras de cabañas vinculados y dependientes de estos centros (Gómez Toscano, 2006, 40).

Fuera de esta zona, los recientes descubrimientos arqueológicos en el centro y sur de Portugal han puesto de manifiesto la importancia de esta área en los momentos previos a la presencia fenicia. La evidencia arqueológica sugiere que las élites locales, ubicadas en poblados centrales dotadas de cercos defensivos, no sólo controlaban e interactuaban con otras zonas peninsulares, como indican los materiales que les vinculan con el Bajo Guadalquivir y la Meseta, sino también con el comercio marítimo a larga distancia con otras regiones atlánticas europeas. Estos poblados en altura ubicados en la confluencia de vías de comunicación o junto a recursos estratégicos controlan la producción de su territorio donde despliegan una red de poblamiento en sus proximidades a corta y media distancia (Monge Soares, 2005; Mataloto, 2005).

El mayor volumen de datos corresponde al yacimiento del castro de Ratinhos (Moura) [ $\mathrm{n}^{\circ} 3$ ] - (Figs.: 1.1 y 2.1) al ser objeto de un intenso proyecto de investigación y gestión. Éste se sitúa en el margen derecho del Guadiana sobre en un cerro aplanado que domina el territorio circundante y la confluencia del Guadiana con el río Degebe y Ardila. Recientemente las excavaciones lusoespañolas han identificado un poblado amurallado con tres recintos defensivos que delimitaban un área cercana a las dos hectáreas (Berrocal-Rangel y
Silva, 2010, 235). En las áreas intervenidas se localizaron varias líneas defensivas, en la acrópolis y en el flanco norte, estableciendo dos grandes etapas, cuyas dataciones se insertan en el Bronce Final (fases 2: siglos XIII - IX A.C.) y en el Hierro Antiguo (fases la y 1b: siglos IX - VIII A.C.), respectivamente (Berrocal-Rangel y Silva, 2010, 135ss.). La línea defensiva de la vertiente norte, exterior, presenta una técnica de construcción singular en tanto que la técnica edilicia se basó en la nivelación del sustrato rocoso en fuerte pendiente, y la cimentación con grandes lajas de esquisto. Apoyándose en este nivel se levantó una zapata como pared de contención. Encima de esta base se erigió un paramento exterior en talud reforzado por una orla, mientras que el espacio intermedio fue rellenado mediante capas de tierra y piedra más o menos compactas que se contenían al interior por grandes losas de pizarra dispuestas verticalmente y acuñadas con otras bajas en forma de zarpa interior. Este sistema defensivo se complementó con la excavación de un foso con perfil en "V" en la base del talud (Berrocal-Rangel y Silva, 2010, 240-241; Silva, Berrocal y Rodero, 2012). Mientras en la acrópolis, se identificó un sistema defensivo cuya datación se ha situado en el Hierro Antiguo, sin que se niegue la presencia de una fase anterior mínimamente conservada. A rasgos generales el recinto más moderno mantuvo las características esenciales del período anterior pero la excavación en los sondeos de la acrópolis permitió atestiguar la existencia de grandes agujeros de poste regulares y peñas de barro cocido, con huellas de postes menores, lo que evidencia el empleo de madera en el cerco defensivo como refuerzo de los mampuestos (Berrocal-Rangel y Silva, 2010, 235-236). Todo ello nos lleva a proponer un sistema de construcción más complejo donde, al menos el paramento interior, se construyó con mampuestos irregulares dispuestos verticalmente y fortalecidos con una estructura de postes de madera. Esta fase, destruida en su acceso hacia el 760 A.C. con la quema de los postes mayores y la vitrificación de algunas de sus piedras, sería contemporánea en construcción y uso con el santuario oriental documentado en el interior de la acrópolis (Silva, Berrocal y Rodero, 2012) - (Fig.: 2).

Un poblado similar parece haber sido el cercano Outerio do Circo (Beja) [ $\left.n^{\circ} 4\right]$, que se ubica en un cerro amesetado elevado sobre el territorio 
circundante, algo más al interior del Alentejo. Se trata de un yacimiento conocido desde la década de los 70 pero solo recientemente se ha desarrollado una investigación centrada en él. Los trabajos de prospección apuntaron la existencia de un doble recinto defensivo cuyo rango cronológico se situó en la Edad del Bronce a partir de los materiales recogidos en superficie aunque se constato una presencia posterior de época romana (Parreira, 1977; Parreira y Soares, 1982, 112). Las excavaciones más recientes han confirmado dos líneas de muralla ya conocidas, mientras que se mantiene una posible entrada flanqueada por bastiones. Así mismo, la intervención en el "Área 1" documentó uno de los taludes del sistema defensivo. El registro arqueológico manifiesta una ocupación dilatada en el tiempo con materiales que datarían la construcción en el Bronce Final. A su vez, se documentaron fragmentos de barro cocido, interpretados como parte de una empalizada superpuesta a la muralla y un nivel compacto de barro cocido cuya posible función radicaría en ser un refuerzo de la estructura (Serra y Porfírio, en prensa).

Más al norte, en Corôa do Frade (Évora) [ ${ }^{\circ}$ 5], yacimiento conocido desde la década de los sesenta, se documento un sistema defensivo contemporáneo a los dos anteriores. La ocupación de este núcleo se ha interpretado unida a Castelo do Giraldo como un punto de control territorial (Paço y Ventura, 1961). En 1971 se realizaron dos sondeos sobre la supuesta muralla, cuyos materiales permitieron a José M. Arnaud proponer una datación entre el 900 y 600 a. C. (Arnaud, 1979, 90), sin embargo, posteriormente amplió su ocupación a un rango de edad entre 1000 a.C. hasta el 700 a.C. (ibídem, 1995, 43).

En la planimetría publicada se puede identificar la existencia de un acceso en la zona oriental del yacimiento. Este acceso, a tenor por los datos deducibles de la planimetría, se caracteriza por presentar una entrada reforzada a cada flanco por un bastión/torre (Arnaud, 1979, 60, fig. 2). Sin embargo, las prospecciones que se realizaron a finales de la década de los noventa generaron otra planimetría del recinto defensivo en el que no se aprecian ni las obras de flanqueo ni la entrada al asentamiento (Burgess et alii, 1999, 139, fig. 6).

En el margen derecho del Guadiana se localiza el yacimiento de Passo Alto (Ficalho) [ $\left.\mathrm{n}^{\circ} 6\right]$, conocido a partir de los trabajos de A. M. Soares (1984, 2003..). Se ubica sobre un espigón fluvial aprovechando las pronunciadas pendientes del Chanza y del Vidigâo y donde la muralla refuerza la inaccesibilidad natural cerrando el único acceso fácil al yacimiento. Las intervenciones de 1984, 1987 y 2005 permitieron constatar la técnica de construcción de la muralla. Ésta estaba constituida por dos paramentos. El interior estaba construido por grandes lajas y bloques de pizarra y la cara exterior por piedras sobrepuestas. El espacio intermedio entre ambas obras fue rellenado de tierra y piedras pequeñas (Soares, 2003, 307). Al interior de la muralla se observaron numerosos bloques informes de piedra que presentaban vitrificaciones como consecuencia del sometimiento de éstas a altas temperaturas provocadas por un incendio de la muralla al incorporar elementos lígneos en la cortina amurallada (Correia, 1995, 251; Soares, 1996, 103). Junto a tales defensas se constató la presencia de un campo de piedras hincadas cuya datación, tras ser debatida en los últimos años, se dató finalmente por C14 en el siglo VIII a. C. (Soares, 2007,173).

Más allá de los centros fortificados alentejanos anteriormente descritos, el registro arqueológico ofrece varios yacimientos donde se han documentado materiales que apuntan a una ocupación protohistórica durante el tránsito del II al I milenio. A pesar de que los datos corresponden a recogidas de materiales en superficie, las evidencias arqueológicas apuntan indican un proceso creciente de control del territorio y de complejidad socio-política.

\section{EL IMPACTO COLONIZADOR Y LA ACUL- TURACIÓN: LAS MURALLAS ORIENTALI- ZANTES}

La información disponible sobre la arquitectura militar en la zona es reducida a causa de los diversos factores que han sido apuntados recientemente (Blánquez, 2008, 147) junto a la ausencia de excavaciones en extensión. Solo en los últimos años el panorama científico ha cambiado y poco a poco comienzan a desarrollarse proyectos de investigación que intentan paliar estas carencias.

La llegada de poblaciones orientales a la Península supuso no solamente la fundación de establecimientos comerciales de diversa entidad a lo largo de la costa mediterránea y atlántica sino 
que también condujo a un proceso de interacción entre las poblaciones coloniales y autóctonas. $\mathrm{La}$ naturaleza y cronología de ambos procesos ha sido ampliamente debatida en la historiografía peninsular (Mederos 2005; González Wagner, 2005; Aubet, 1999; López Castro, 2000; González Wagner y Alvar, 1989...) abordando la cuestión desde diversos paradigmas y construcciones teórico-metodológicas. Este debate junto a nuevos hallazgos contribuyen a reconstruir este período protohistórico.

Sea como fuere, en lo que se refiere a los principales núcleos rectores semitas, el establecimiento inicial fenicio estuvo marcado tanto por la antigua isla de Cádiz como por la desembocadura del río Guadalete, sedes de la antigua Gadir.

En esta última, el paradigmático yacimiento del Castillo de Doña Blanca [ ${ }^{\circ} 7$ ] ha permitido identificar un recinto defensivo datado en los primeros momentos de la colonización. La muralla, del siglo VIII a.C., se ha constatado especialmente bien en la zona norte del yacimiento con un paramento correspondiente al lienzo exterior de la muralla y otro de un bastión, junto a parte de su planta circular (Ruiz Mata, 2001, 263). Ambas construcciones se han datado a mediados del siglo VIII a.C. y su final hacia principios del siglo VI a.C. a partir de los restos hallados al exterior de las construcciones. El paramento está construido sobre un zócalo de mampostería de aproximadamente un metro de altura que sobresale de su cara externa unos 80 centímetros y apoya sobre una plataforma de tierra rojiza. A su vez toda la cara externa debió estar enlucida con un revoco de arcilla blanquecina que daba al conjunto un aspecto homogéneo (Barrionuevo; Ruiz Mata y Pérez Pérez, 1997, 117; Ruiz Mata, 2001, 264). La obra defensiva debía rematarse con una alzado de a juzgar por la existencia de gruesos estratos de barro con nódulos de cal junto a la muralla (Escacena, 2001, 110; Escacena, 2002).

Anterior en el tiempo se fecha, incluso, la primera fase de ocupación del importante yacimiento de Los Castillejos de Alcorrín (Manilva, Málaga) - [nº 8] - (Fig.: 1.3 y 2.3), donde el registro radiocarbónico demuestra una fecha de partida de finales del siglo IX A.C. (Mielke en Marzoli et alii, 2009, 133ss.). Y quizá en este momento pionero deba fecharse una muralla de grandes bloques pétreos irregulares que, con doble para- mento, constituye un zócalo de 1,70 m. de altura sobre los que los excavadores suponen un lienzo de adobes (Marzoli et alii 2010:154). Nueve torres o bastiones de planta semiesférica, y equidistantemente emplazados, refuerzan la capacidad defensiva del tramo más accesible de esta muralla y al carácter poco indígena de su construcción por más que la cerámica procedente de este poblado sea aplastantemente de factura peninsular (ibidem, 167ss., esp.170). Quizá la localización de una segunda línea de muralla, rodeando la zona más alta del asentamiento precedida de un foso (ibídem, 158; Lám. 2) recuerde en mucho la disposición documentada en Ratinhos, pero estructuralmente parece claro que son construcciones totalmente distintas. Quizá si hay algún paralelo es con la segunda fase de las murallas interiores de ambos yacimientos -las dos rodeando sus acrópolis-, donde la presencia de agujeros está bien constatada en el caso portugués y parece haber sido localizada en el malagueño. La presencia de abudante madera en la construcción de ambas también parece confirmada (Berrocal y Silva 2007:181; Silva, Berrocal y Rodero 2011; Marzoli et alii 2010:159 y 174). Y también las fechas radiocarbónicas de ambas construcciones son sorprendentemente similares, cir. 830 A.C. para el castro portugués y cir. 814 A.C. para el poblado malagueño (ibídem). Parece claro que ambas construcciones, pese a la lejanía espacial entre ambas, son ejemplos de las más antiguas fortificaciones de clara adscripción fenicia peninsular, ambas fuertemente condicionadas por los ambientes indígenas del Bronce Final.

Al interior, en el área onubense, Tejada la Vieja [n ${ }^{\circ}$ 9] - (Fig.: 1.2 y 2.2) es el poblado amurallado mejor conocido, tanto en sus defensas como en el urbanismo. Sus inicios se fechan entorno al siglo VIII A.C. y desde el principio se dotó de un recinto defensivo con unas características bien conocidas en la historiografía. La fortificación en su primera fase estuvo formada por dos lienzos, cuyo paramento exterior presenta una ligera inclinación hacia el interior formando una estructura en talud, y cuyo espacio interno se rellenó con tierra y piedras. El recinto defensivo se complementó con torres de planta circular (García Sanz 1987; Ruiz Mata 1998,202; Fernández Jurado y García Sanz 2001; Fernández Jurado 2003). Posteriormente, en torno al siglo VI a.C., se reforzó mediante un segundo lienzo y con 
contrafuertes de planta rectangular, al mismo tiempo que se configuraba la reordenación del urbanismo (Fernández Jurado 2003, 44)

Si bien el origen del recinto defensivo de Niebla (Huelva) se ha situado con una cronología pre-fenicia, será en el período orientalizante cuando se dote de una nueva fortificación. En este sentido, la construcción de la segunda fase se realizó mediante una estructura compartimentada mediante tres paramentos paralelos entre sí unidos por muros a perpiaños o riostras perpendiculares a ellos. El espacio interior no fue excavado por lo que no es posible dilucidar si estamos ante una muralla de cajones.

La Arqueología también ha identificado una ocupación de época proto-orientalizante en Carmona (Sevilla) - $\left[n^{\circ} 10\right]$. En este asentamiento ubicado sobre una meseta que domina la campiña, los últimos descubrimientos en la Puerta de Sevilla y en la calle José Arpa n 3 (Gil et alii, 1987a; 1987b) han documentado un sistema defensivo compuesto por una muralla con el paramento exterior en talud y dotado de bastiones circulares. Este recinto defensivo fue datado en el Hierro I y destruido en un episodio violento en la segunda mitad del siglo VI a.C. (Jiménez, 1989; Escacena, 2001; 2002; Vázquez Paz, 2001, 179).

Cerca de esta localidad se ubica la Mesa de Setefilla (Lora del Río) [ $\left.\mathrm{n}^{\circ} 11\right]$ que controla el paso desde las últimas estribaciones de Sierra Morena al valle del Guadalquivir (Aubet, 1989, 311) y posee un claro dominio sobre los territorios circundantes (Aubet, 1989, 298). La adscripción cronológica de esta edificación defensiva se situó a mediados del II milenio debido a la dificultad estratigráfica y lo reducido de la intervención (Aubet, Serna, Escacena y Ruiz Delgado, 1983). Sin embargo, las recientes aportaciones de El Carambolo y el replanteamiento que conllevan sobre la datación relativa de ciertos materiales, como la cerámica pintada, obliga a reconsiderar la fecha de la fortificación de Setefilla bajando su rango varios siglos. A esto se añade a que los rasgos edilicios parecen guardar muchas similitudes con otros recintos protohistóricos del área. Los datos disponibles de la muralla pertenecen a las estructuras documentadas en los Cortes 1. La construcción se constituye a partir de dos muros paralelos, realizados a base de mampostería. Estos paramentos se hallaban separados entre sí aproximadamente 2 metros, espacio que quedaba relleno de piedras de gran tamaño. Los excavadores interpretaron dicha construcción como una potente muralla o contrafuerte con un espesor de 5 metros que se había reforzado mediante los paramentos paralelos (Aubet et alii, 1983, 22; Aubet, 1989, 301). Sobre ella se documentó un piso grueso de barro cocido amarillento que a intervalos presentaba una especie de alineación horizontal de adobes. Dicha capa cegó la estructura de carácter defensivo anteriormente descrita. De naturaleza similar es el nivel V y VI del Corte 2. En dicha zona, se documento un estrato (nivel $\mathrm{V}$ ) formado por arcillas de color anaranjado uniformes mezcladas con adobes caídos. El nivel VI lo constituye una estructura de adobes que presenta una alineación uniforme y que se constató en la base del nivel $\mathrm{V}$.

En torno a la paleo-desembocadura del Guadalquivir y dentro del área más inmediata de Doña Blanca, la Arqueología también ha constatado otros núcleos posiblemente con edificaciones defensivas - Mesa de Gandul, Lebrija (Sevilla) [ $\mathrm{n}^{\circ} 12$ y 13] - cuyo conocimiento es reducido ya que los datos proceden de prospecciones de superficie y pequeños sondeos estratigráficos que confirmarían la ocupación de estos centros de época tartésica; o Cerro San Cristóbal y Chiclana de la Frontera, cuyos recintos defensivos compartirían similitudes arquitectónicas con otros núcleos del área tartésica (Juárez et alii, 1998; Escacena, 2001; Bueno y Cerpa, 2008).

Siguiendo el eje del Guadalquivir, en el yacimiento de Ategua (Córdoba) - $\left[n^{\circ} 14\right]$ en una campaña puntual en 2004, se localizaron los restos constructivos de un recinto defensivo que se dató en el siglo VIII a.C. Según sus excavadores, la estructura a pesar de lo exiguo de los datos presentaría unas características similares a las localizadas en el área del Bajo Guadalquivir. Este lienzo murario del que sólo se ha documentado el paramento exterior coincidiría con los restos de otro ya localizado por Blanco en la década de los ochenta (López Palomo, 2008).

No sólo Doña Blanca se configura como un foco de aculturación hacia el área tartésica, las factorías semitas de la costa mediterránea cons- 
tituyen otros puntos de interacción hacia el hinterland malagueño, el Alto Guadalquivir y las vías que los conectan a través de las Béticas con las sociedades indígenas. Los recientes descubrimientos evidencian una implantación más segura y firme (Schubart, 2003; García Alfonso, 2007).

En el interior malagueño el poblamiento indígena presenta signos de núcleos amurallados en la transición del II al I milenio en momentos previos a la colonización semita. No obstante, el conocimiento de su construcción como de su estructura, así como de su cronología concreta, aún quedan pendientes. Se percibe al mismo tiempo tanto una continuación en el poblamiento amurallado de etapas previas (Cerro de la Encina, Peñón de la Reina o el Llano de la Virgen) como la ocupación de nuevos lugares como Capellanía (García Alfonso, 2007, 241).

En el litoral atlántico portugués, el impacto de la colonización semita es cada vez más evidente en la cultura material y en la edilicia (Varela Gomes, 2001). A este respecto los intercambios fenicios con los indígenas alcanzaron las costas del centro y norte de Portugal, fundando algunos establecimientos o enclaves próximos a las grandes vías de penetración hacia el interior.

Bajo el actual casco urbano de Tavira (Faro) [ $\left.\mathrm{n}^{\circ} 15\right]$ en la desembocadura del río Gilão se localizó un asentamiento con una gran influencia fenicia. Se ubica en la colina de Santa María a 8 metros sobre el nivel del mar. En los trabajos arqueológicos se distinguieron dos fases (MF 1 y MF2). En la primera edificación se levantó un recinto defensivo de 4 metros de espesor que se complementó con una obra de flanqueo cuya planta no se registró al quedar inmersa en la unión de ambas fases constructivas. Posteriormente, esta cortina amurallada se reforzó mediante la construcción de la segunda edificación. Se trata de una muralla formada por dos muros paralelos y perpiaños perpendiculares con un espesor variable debido al trazado del recinto (Maia 2001 ,124). A esta estructura se le adosó un tercer paramento al exterior en talud, siguiendo un ángulo de $70-80^{\circ}$. Dicha obra fue revestida desde la roca hasta la altura de 1,10-1,20 metros con un revoco de barro amarillo-verdoso (Maia 2001,125).

Más al este se situaba el Cerro de Rocha Branca (Silves) [ $\left.n^{\circ} 16\right]$ donde se atestiguó una muralla en la que se han podido discernir dos fases constructivas. La primera, con espesor de 1,50 metros, definía un espacio trapezoidal a partir del cual se adosaban unos muros perpendiculares delimitando habitaciones de planta rectangular (Correia, 2001, 60; Varela Gomes, 1993, 76-77).

Mientras, por otra parte, la remodelación correspondiente a la segunda supone un cambio en el estrategia defensiva al incorporarse nuevos recursos poliorcéticos. Esta reforma se ha datado en el siglo a finales del siglo VI a. C. El trazado no solo quedaba retranqueado respecto a la primera sino que su trazado describía un segmento de círculo reforzado por las torres (Varela Gomes, 1993, 77). Además, también en el litoral del Algarve, se ubica Castro Marim donde las actuaciones arqueológicas han registrado un recinto defensivo orientalizante datado en el siglo VIII a.C., pero cuyos detalles constructivos son escasos por el momento (Arruda, 1983-84, 1996; 1999-2000).

\section{Conclusiones}

Los inicios de una red compleja de poblamiento en el Mediodía peninsular se sitúan en las postrimerías del Bronce Final, donde se comprueba la emergencia de jefaturas y donde poblados amurallados actúan como ejes y enclaves de dicho entramado. El registro material con presencia de cerámica bruñida así como la ausencia de importaciones apunta a que estos recintos son erigidos en un momento anterior a la presencia fenicia, suposición actualmente confirmada por numerosas dataciones radicarbónicas.

La ubicación topográfica de estos asentamientos desvela que se emplazan en lugares destacados, con un elevado índice de pendiente sobre el entorno que dificulta el acceso y con un gran dominio visual sobre el territorio inmediato. A las ventajas naturales se suman las construcciones defensivas que responden a técnicas edilicias originales. En este sentido esta arquitectura se configura como un recurso sencillo dentro de un concepto de poliorcética basado en la utilización de los condicionantes del relieve. Esta inaccesibilidad natural se complementa con la construcción de una cerca defensiva de una singularidad estructural sorprendente. 


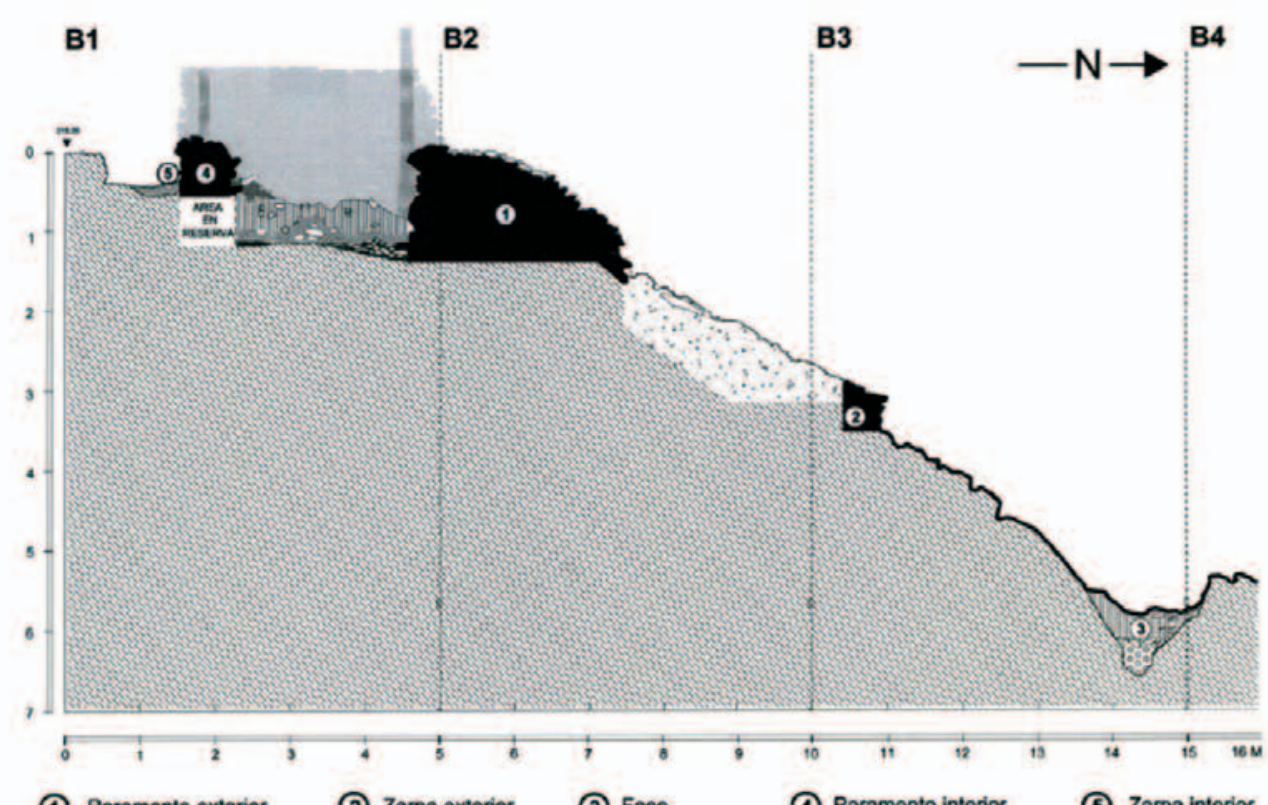
(1) Paramento exterior
(2) Zarpa exterior
(3) Foso
(4) Paramento interior
(5) Zarpa interior
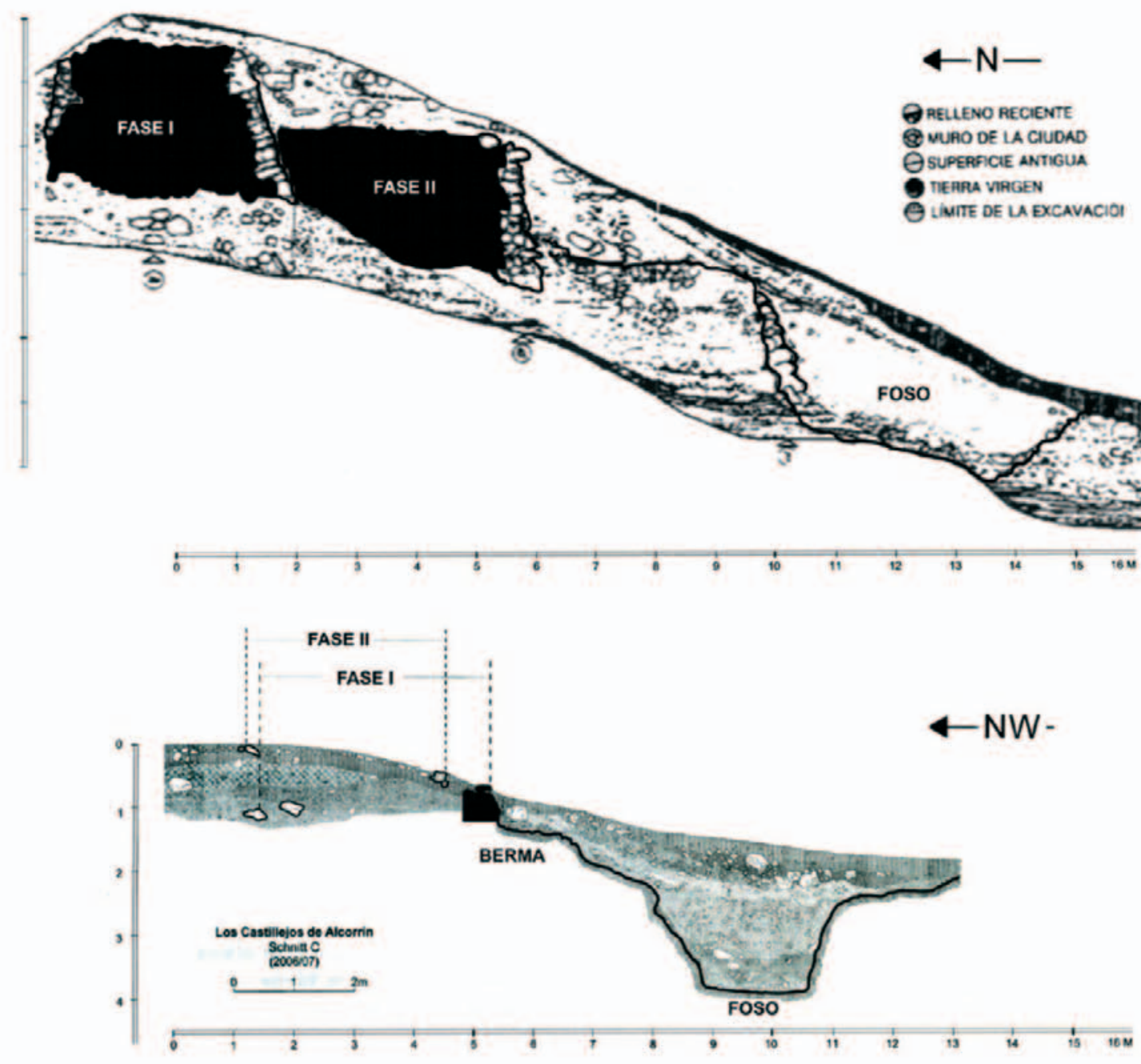

Figura 2: Secciones de murallas y defensas del Hierro Antiguo (Ss. IX-VIII A.C.); 1. Ratinhos, Moura (según Silva, Berrocal y Rodero 2012); 2. Tejada la Vieja (modificado a partir de Fernández Jurado 1987); 3. Los Castillejos de Alcorrín, (Modificado a partir de Marzoli et alii 2009), todos a la misma escala. 
Los registros arqueológicos de Ratinhos y de Outerio do Circo, ambos en el Alentejo meridional portugués, se configuran como paradigmas de estos emplazamientos precoloniales, con el uso de mampostería en paramentos exteriores en talud, junto al empleo de grandes losas y rellenos de tierra y piedra. De igual forma en éstos y otros contemporáneos es llamativa la carencia de obras de flanqueo salvo, quizá, si tenemos en cuenta los datos procedentes de las prospecciones, en los puntos de mejor acceso donde bastiones sobresalientes reforzarían la entrada. También estos ejemplos muestran varios recintos bien adosados, como Corôa do Frade, o bien concéntricos como Ratinhos, Castelo do Giraldo y Alto do Castelinho da Serra. Sin embargo, debe concretarse en la mayor parte de ellos la datación de los distintos recintos para establecer su sincronía o diacronía.

Las prospecciones sistemáticas en la cuenca del Guadiana evidencian una gran concentración de núcleos amurallados en esta área. Los datos de los que disponemos apuntan a una cronología amplia dentro del Bronce Final y en algunos casos con perduraciones durante la Edad del Hierro y ya en época romana.

Localmente se observa que debió existir una estrategia de control del territorio vertebrada por asentamientos amurallados de cierta entidad de los que dependerían otros de menor tamaño. En suma, es factible defender la existencia de estrategias de defensa complejas del territorio al igual que una evolución socioeconómica y política mayor de lo que se ha pensado y de lo que se ha propuesto a partir de las sencillas construcciones domésticas en el curso del Guadiana, zona onubense o el interior malagueño en momentos previos a la colonización fenicia.

Este desarrollo de los sistemas defensivos propios de cada núcleo, junto a un control efectivo del entorno más inmediato, debe explicarse a partir de un proceso de creciente complejidad social desde el Bronce Final I hasta los inicios de la colonización, a pesar de que se entienda como un proceso paulatino con ritmos diferenciales. El impacto colonizador vino a amplificar esta dinámica cuyo reflejo se plasma en una intensificación y transformación de los modos económicos vigentes dentro de una jerarquización y monopolización del poder político y social, las cuales se hacen patentes en el análisis espacial de estas áreas.
A partir de mediados del siglo IX A.C., el panorama de la arquitectura defensiva en el Sur peninsular se transforma por la influencia de las técnicas edilicias coloniales. El registro arqueológico parece apuntar a la instalación de un modelo de fortificación que ya ha sido advertida por distintos investigadores (Escacena 2002; Escacena y Troncoso 2001). Se trata de un tipo de construcción que tiene sus manifestaciones más antiguas en los emporios fenicios - Alcorrín, Castillo de Doña Blanca, Carmona y posiblemente en Toscanos - a principios del siglo VIII e incluso inicios de la centuria anterior (Marzoli et alii 2010; Arnold y Marzoli 2009; Schubart 2006...). Rápidamente se implantó en las zonas más próximas a los centros semitas, como evidencia Niebla, Tejada la Vieja, San Cristóbal,..., aunque no responde completamente a los modelos próximoorientales sino parece ser más una adaptación estructural al espacio peninsular, siguiendo una economía técnica con pautas orientales. De igual manera su influencia temprana se constata en los poblados indígenas del Guadiana, con el uso de estructuras interiores de madera que sirven para elevar las cortinas amuralladas verticalmente como se comprueba en la fase moderna de la muralla de la acrópolis de Ratinhos con sus agujeros de poste y pellas de barro con huellas de éstos. Además el hallazgo de asentamientos en llano con vocaciones agropecuarias, como el cercano Rocha de Vigio 2, debieron complementar una estrategia de explotación y control del territorio novedosa entre estas comunidades indígenas (Calado, Mataloto y Rocha, 2007), con un incremento de su entidad y número a partir del siglo VII a.C. favorecido por la demanda de los centros coloniales.

Respecto a las murallas de los primeras colonias peninsulares, el estudio de los niveles de ocupación de Cartago apunta a construcciones peninsulares de similares caracteres en niveles fenicios arcaicos de los siglos VIII-VII a.C. (Rakob, 1998, 26-27; Dorcet et alii, 2003). En este sentido, la sincronía de estas construcciones en los inicios de las factorías semitas en el Mediterráneo occidental indican una confluencia no sólo en los lugares elegidos sino también la erección de los primeros recintos defensivos como respuesta a una misma preocupación geoestratégica. 
Estructuralmente estas obras defensivas se componen de un lienzo amurallado formado por dos paramentos paralelos, cuyo espacio intermedio es rellenado de piedras y tierras, ahorrando esfuerzo en la construcción y material. En ocasiones, a esta estructura se le incorporan unos tirantes transversales o perpiaños que configuran una muralla compartimentada cuyos espacios intermedios son rellenados de tierra y piedra. De este modo, se genera un tipo de muralla denominada "de cajones" (Moret, 1996, 83-84), cuya documentación arqueológica muestra un relleno descrito como una mezcla de tierra y piedra que no aporta ningún suelo de ocupación o habitación (García Alfonso, 1993-1994, 56-57; García Alfonso et alii, 1995, 36-37; Barrionuevo; Ruiz Mata y Pérez Pérez, 1997, 116; Juárez et alii, 1998, 20; Maia, 2001, 124).

En la Península ibérica a este núcleo suele adosarse un tercer paramento al exterior. Éste se edifica en talud aportando el marcado carácter inclinado de los sistemas defensivos orientalizantes. Sin embargo, en la costa sirio-palestina, este tipo de estructuras no presentan las características propias de las técnicas peninsulares. En ellas se constata el glacis como una rampa al pie de la muralla, con una inclinación media de $30-40^{\circ}$, construida para evitar la erosión y también para impedir el acercamiento de torres de asedio y arietes (Burke, 2008, 31 y ss.).

Materialmente, el registro arqueológico evidencia el empleo generalizado de la piedra como material de construcción. El aparejo de la edilicia militar se limita entre el siglo IX y el siglo VI A.C. a la utilización de formas simples, pero rentables por su economía, con el empleo de mampostería careada o sin carear, aglutinadas con arcilla, o a hueso (Rodero, 2005).

El aprovechamiento de las posibilidades del entorno inmediato se manifiesta como una característica no sólo de los sistemas constructivos indígenas sino también de la edilicia colonial en todos sus aspectos, lo cual le otorga uno de sus rasgos definitorios a la arquitectura fenicio-púnica (Barreca, 1989, Prados, 2003). En la parte superior se elevaría un alzado de tapial o adobes, a juzgar por las grandes concentraciones de arcilla y barro que constituyen verdaderos estratos en las estratigrafías de los yacimientos de Castillo de Doña Blanca, Tejada la Vieja (García Sanz, 1987,
99-100; Escacena, 2002, 73) y posiblemente en la Mesa de Setefilla.

Analíticamente las obras de flanqueo suponen uno de los primeros síntomas que permiten identificar una muralla construida para una defensa polifacética y tácticamente compleja. Los datos extraídos de los asentamientos orientalizantes y fenicios nos permiten confirmar la evolución en las plantas de estas estructuras que anteriormente ya habían sido postuladas por diversos investigadores en otros ámbitos (Moret, 1991, 37-38; 1996, 204-205; Berrocal-Rangel, 2005, 51-52). Se ha propuesto un proceso evolutivo en la planimetría de las plantas de torres y bastiones desde unos inicios curvilíneos hacia el ángulo recto o agudo, y las estructuras cuadrangulares-trapezoidales, quizás parejo al desarrollo en la arquitectura doméstica de las plantas ortogonales (Moret, 1996:205).

En este sentido, tanto en las fortificaciones coloniales como en las indígenas parece materializarse esta pauta evolutiva de las defensas. En los primeros ejemplos de obras de flanqueo, que corresponden a cronologías iniciales (circa 800700 ), se percibe un desarrollo en planta de tendencia curvilínea. De este modo se documentan estructuras curvilíneas en Castillo de Doña Blanca (s. VIII A.C.), Carmona (s. IX-VIII A.C.), Tejada la Vieja (s. VIII A.C.), Setefilla (mediados del II milenio), aunque éste último con reservas en cuanto a su cronología, frente a las trapezoidales del recinto exterior de Alcorrín (s. VIII A.C.).

No obstante, algunos de los casos no ofrecen estructuras fiables documentadas aunque existen indicios que hacen pensar en su posible existencia. En los Castillejos de Teba y los Castrejones de Aznalcóllar se defiende esta posibilidad, mientras que en el Cerro de San Cristóbal no permite establecer la existencia o carencia de obras de flanqueo a tenor de los datos disponibles. En ambos casos mantendrían una planta curvilínea.

Sin embargo posteriormente, ya en el siglo VII-VI A.C., se produce una transformación al incorporarse al repertorio de los recursos defensivos las plantas cuadrangulares como evidencian los sistemas defensivos de Tejada la Vieja (Huelva) y Castro Marim (Algarve), cuyos rangos de uso se sitúan entre el siglo 600 y 400 A.C., o en las cuenca media y alta del Guadalquivir, unidos a nuevos recintos amurallados cuyas caracte- 
rísticas se sitúan próximas al área onubense y Bajo Guadalquivir, a partir del siglo VI A.C. (poblados de Torreparedones, las Atalayuelas, Puente Tablas...: Castro et alii, 1987; Cunliffe y Fernández Castro, 1987 y 1999; Ruiz, Molinos y Choclán, 1991, 115-116).

Este modelo colonial peninsular se expandió desde el área nuclear hacia la periferia desde los inicios de su presencia a finales del siglo IX A.C. primero en la forma de técnicas constructivas concretas y adaptadas a la tradición indígena, después, durante el siglo VIII A.C., manifestando la adopción de ideas y conceptos defensivos que se traducen en las "copias" de los modelos coloniales partir del siglo VII a.C. En este sentido, el registro arqueológico evidencia que en este rango temporal emergen núcleos amurallados que siguen el prototipo colonial, tanto en el valle medio-alto del Guadalquivir - Puente Tablas (Jaén), Torreparedones (Córdoba), Las Atalayuelas (Jaén), y el Cerro de las Norias (Jaén) (Castro et alii, 1987; Cunliffe y Fernández Castro, 1987, 1999; Ruiz, Molinos y Choclán, 1991, 115116), como en el sureste peninsular - los Almadenes (Sala Sellés y López Precioso, 1995).

\section{Agradecimientos:}

Queremos mostrar aquí nuestro más sincero agradecimiento a Rafael Caso, Fernando Prados, Miguel Serra y a todos aquellos cuyos comentarios y revisiones han brindado a este artículo.

\section{BIBLIOGRAFÍA}

ACQUARO, E.; FERRARI, D. eds., (2004): I Fenici. L'Oriente in Occidente. Biblioteca di Vita Senato, Milano.

ALMAGRO-GORBEA, M. (1998): "Precolonización y cambio cocio-cultural en el Bronce Atlántico" en Oliveira, S. (ed.), Existe uma Idade do Bronze Atlântico?. Trabalhos de Arqueologia 10: 81-100.

ARNOLD, F.; MARZOLI, D. (2009): “Toscanos, Morro de Mezquitilla und Las Chorreras im 8 und 7 Jh. V. Chr. Siedlungsstruktur und Wohnhaustypologie.", en S. Helas y D. Marzoli, eds., Phönizisches und Punisches Städtewesen: 437-460.

ARNAUD, J. (1979): “Corôa do Frade: fortificação do Bronze Final dos arredores de Èvora. Escavações de 1971-1972”. Madrider Mitteilungen, 20: 56-100.
ARRUDA, A. M. (1983-1984): “Escavações arqueologicas no Castelo de Castro Marim. Relatório dos Trabalhos de 1983". ClioArqueologia, 1: 245-248.

ARRUDA, A. M. (1996): "O castelo de Castro Marim" en J. Alarcão, De Ulisses a Viriato. O primerio milènio a.C. Museo Nacional de Arqueología. Lisboa: 95-111.

ARRUDA, A. M. (1999-2000): "Los Fenicios en Portugal. Fenicios y mundo indígena en el centro y sur de Portugal (siglos VIII-VI a.C.)". Cuadernos de Arqueología Mediterránea, 5-6.

AUBET, Ma . E. (1989): "La Mesa de Setefilla: la secuencia estratigráfica del Corte 1 " en $\mathrm{M}^{\mathrm{a}}$. E. Aubet (ed.), Tartessos, Arqueología protohistórica del Bajo Guadalquivir. Ausa: 297-338.

AUBET, Ma . E. (1994): Tiro y las colonias fenicias de Occidente. Crítica Arqueología, Barcelona.

AUBET, M ${ }^{\mathrm{a}}$. E.; SERNA, Mº. R.; ESCACENA, J. L.; RUIZ DELGADO, M. M. (1983): La Mesa de Setefilla (Loria del Río, Sevilla). Campaña de 1979. Excavaciones arqueológicas en España 122. Ministerio de Cultura.

BARRIONUEVO, F. J.; RUIZ MATA, D. y PÉREZ PÉREZ, C. (1997): "Fortificaciones de casernas del Castillo de Doña Blanca (El Puerto de Santa María, Cádiz)". XXIV Congreso Nacional de Arqueología, Cartagena: 115-121.

BELÉN DEAMOS, Ma . (1995) "El yacimiento tartésico de Niebla" en Actas del Congreso Conmemorativo del $V$ Symposium Internacional de Prehistoria Peninsular: Tartessos 25 años después (1968-1993). Jerez de la Frontera: 359-381.

BENDALA GALÁN, M. (2000): Tartesios, iberos y celtas. Pueblos, culturas y colonizaciones de la Hispania antigua., Temas de hoy, Madrid.

BENDALA, M. y BLÁNQUEZ, J. (1997): “El legado bélico mediterráneo. Tartessos y el mundo ibérico" en La guerra en la Antigüedad. Una aproximación al origen de los ejércitos en Hispania. Ministerio de Defensa: 135-155.

BENDALA， M. y BLÁNQUEZ, J. (2002-2003): "Arquitectura militar púnico-helenística en Hispania”. CUPAUAM, 28-29: 145-159.

BERROCAL-RANGEL, L. (1995): “Arqueología de las fortificaciones griegas III. Repercusiones entre púnicos, íberos y celtas". Revista de Arqueología 166: 24-35. Madrid.

BERROCAL-RANGEL, L. (2004): "La defensa de la comunidad: sobre las funciones emblemáticas de las murallas protohistóricas en la Península Ibérica". Gladius, XXIV: 27-98. 
BERROCAL-RANGEL, L.; P. MORET, eds. (2007): Paisajes fortificados de la Edad del Hierro. Las murallas protohistóricas de la Meseta y la Vertiente atlántica en su contexto europeo., BAH, 28, Madrid.

BERROCAL-RANGEL, L.; A.C. SILVA (2010): $O$ Castro dos Ratinhos (Barragem de Alqueva, Moura). Escavaçôes num povoado protohistórico do Guadiana, 2004-2007., O Arqueólogo Português, Suplemento $n^{\circ}$ 6, Lisboa.

BLANCO FREIJEIRO, A. (1983): “Ategua”. Noticiario Arqueológico Hispánico, 15: 95-133.

BLANCO FREIJEIRO, A; ROTHENBERG, B (1981): Exploración arqueometalúrgica de Huelva. Labor. Madrid.

BUENO, P. y CERPA, J. A. (2008): "Un nuevo enclave fenicio descubierto en la Bahía de Cádiz: el Cerro del Castillo, Chiclana”. SPAL,17: 169-206.

BURKE, A. (2008): Walled up to heaven the evolution of Middle Bronze Age fortification strategies in the Levant. Studies in the archaeology and history of the Levant, 4

CAMPOS, J. M.; GÓMEZ TOSCANO, F. y PÉREZ MACÍAS, J. A. (2006): Ilipla-Niebla. Evolución urbana y ocupación del territorio. Universidad de Huelva.

CALADO, M.; BARRADAS, M.; MATALOTO, R (1999) - Povoamento proto-histórico no Alentejo Central. Revista de Guimarães - volumen especial - Actas do Congresso de Proto-História Europeia. Guimarães. Vol. I, 363-386.

CELESTINO PÉREZ, S.; JIMÉNEZ ÁVILA, J.J. (2005): El Período Orientalizante. Actas III Simp. Int. Arqueología de Mérida. Protohistoria del Mediterráneo Occidental. Anejos AEspA, XXXV, Madrid.

CELESTINO PÉREZ, S.; RAFEL, N.; ARMADA, X.L. (2008): Contacto cultural entre el Mediterráneo y el Atlántico (siglos XII-VIII ane). La precolonización a debate., Serie Arqueológica 11, CSIC - Escuela Esp. Hist. y Arq. Roma, Madrid.-

CORREIA, V. H. (1996): "Os povoados da $1^{\circ}$ Idade do Ferro do Sul de Portugal" en J. Alarcão, De Ulisses a Viriato. O primerio milènio a.C. Museo Nacional de Arqueología. Lisboa: 82-87.

CORREIA, V. H. (2001): “Arquitectura Oriental e Orientalizante em territòrio português: uma revisão en D. Ruiz Mata y S. Celestino Pérez (eds.), Arquitectura oriental y orientalizante en la Península Ibérica. Centro de Estudios del Próximo Oriente: 57-69.
COSTA, B.; FERNÁNDEZ, J.H., eds. (2002): La colonización fenícia en Occidente. Estado de la investigación a inicios del siglo XXI. (XVI ${ }^{\mathrm{a}}$ Jornadas Arqueología Fenicio-Púnica (Eivissa 2001), Eivissa.

COFFYN, A. (1985): Le Bronze Final Atlantique dans la Peninsule Iberique. Paris.

CUNLIFFE, B. y FERNÁNDEZ CASTRO, Mª C. (1999): The Guadajoz Proyect. Andalucia in the first Millenium BC. Volume 1. Torreparedones its hinterland. Oxford University Committe for Archaeology (Monograph 47).

DÍES CUSÍ, E. (2001): "La influencia de la arquitectura fenicia en las arquitecturas indígenas de la Península Ibérica" en D. Ruiz Mata y S. Celestino Pérez (eds.), Arquitectura oriental y orientalizante en la Península Ibérica. Centro de Estudios del Próximo Oriente: 69-123.

ESCACENA, J. L. (2001): "Podando a Carmo. Perfiles del sustrato turdetano" en Actas del II Congreso de Historia de Carmona: Carmona romana. Carmona, 29 de septiembre a 2 de octubre de 1999. Universidad de Sevilla.

ESCACENA, J. L. (2002): "Murallas fenicias para Tartessos. Un análisis darwinista". SPAL 11: 69105. Sevilla.

ESCACENA, J. L. y FERNÁNDEZ TRONCOSO, G. (2001): "Tartessos fortificado" en Congreso Internacional: Fortificaciones en el entorno del Bajo Guadalquivir. Alcalá de Guadaira: 109-127.

FERNÁNDEZ JURADO, J. (1987): Tejada la Vieja: una ciudad protohistórica. Huelva Arqueológica, IX.

FERNÁNDEZ JURADO, J. (2000): “Tartessos. La memoria contada" en D. Ruiz Mata (ed.), Fenicios e indígenas en el Mediterráneo y Occidente: modelos e interacción. Actas de los Encuentros de Primavera de la Universidad de Cádiz en el Puerto de Santa María. 1998: 99-107.

FERNÁNDEZ JURADO, J. (2003): “Indígenas y fenicios en Huelva". Huelva Arqueológica, 18: 33-51.

FERNÁNDEZ JURADO, J. y GARCÍA SANZ, C. (2001): "Arquitectura Orientalizante en Huelva" en D. Ruiz Mata y S. Celestino Pérez (eds.), Arquitectura oriental y orientalizante en la Península Ibérica. Centro de Estudios del Próximo Oriente: 159-173.

FERREIRA, C. A. (1992): "Escavações no povoaso fortificado das Mesas do Castelinho (Almodòvar). Relatorio preliminar. Vipasca, 1: 19-37. 
FRANKENSTEIN, S. (1997): Arqueología del colonialismo. El impacto fenicio y griego en el sur de la Península Ibérica y el suroeste de Alemania. Crítica.

GARCÍA ALFONSO, E. (1993-1994): “Los Castillejos de Teba (Málaga). Excavaciones de 1993. Estratigrafía de lo siglos VIII-VI A. C." Mainake XV-XVI: 45-73.

GARCÍA ALFONSO, E. (2007): En la orilla de Tartessos indígenas y fenicios en las tierras malagueñas, siglos XI-VI a. C. Fundación Málaga.

GARCÍA ALFONSO, E. ET ALII (1995): "Valle del Guadalteba: una región idónea para el estudio del indigenismo precolonial". Revista de Arqueología 165: $32-42$.

GARCÍA SANZ, C. (1987): "Excavación de la muralla de Tejada" en J. Fernández Jurado, Tejada la Vieja: una ciudad protohistórica, en Huelva Arqueológica, IX: 93-105.

GARCÍA SANZ, C. (2003): “Unas ruinas merecen tanto escritos? Huelva Arqueológica, 18: 7-31.

GIBSON, C.; CORREIA, V. H. y BURGESS, C. B. (1998): "Alto do Castelinho da Serra (Montemoro-Novo, Èvora, Portugal). A preliminary report on the excavations at the Late Bronze Age to Medivela site, 1990-1993. Journal of Iberian Archaeology , 0: 189-244.

GIL, Ma . S. et alii (1987a): "Informe de las excavaciones arqueológicas en el solar de José Arpa núm. 3 (Carmona, Sevilla). Anuario Arqueológico de Andalucía, III, Actividades de Urgencia: 361-365.

GIL, Ma . S. et alii (1987b): "Informe de las excavaciones arqueológicas en el yacimiento de Barbacana Alta (Carmona, Sevilla)". Anuario Arqueológico de Andalucía, III, Actividades de Urgencia: $355-360$.

GOMES VARELA, M. (1993): "O establecimiento fenicio-púnico do Cerro da Rocha Branca (Silves)". Estudos Orientais 4: 73-107.

GÓMEZ TOSCANO, F. (2006): "El final de la Edad del bronce entre el Guadiana y el Guadalquivir. Síntesis histórico-arqueológica según las más recientes evidencias". Madrider Mitteilungen, 47: 24-42.

GÓMEZ TOSCANO, F.; CAMPOS, J.M. (2001): Arqueología de la Ciudad de Huelva (19662000). Universidad de Huelva.

GÓMEZ TOSCANO, F.; BELTRÁN PINZÓN, J. M. (2003): "Seguimiento arqueológico de apoyo a la restauración de las murallas de Niebla (Huelva): fases de amurallamiento en el tramo Puerta de Sevilla-Torre 26". AAA 2003, III: 640-652.
GONZÁLEZ DE CANALES, F.; SERRANO, L., J. LLOMPART (2004): El emporio fenicio precolonial de Huelva (ca. 900-770 a.C.). Biblioteca Nueva, Madrid.

GONZÁLEZ PRATS, A. (2000): "Fenicios e indígenas en el Levante peninsular" en D. Ruiz Mata (ed.), Fenicios e indígenas en el Mediterráneo y Occidente: modelos e interacción. Actas de los Encuentros de Primavera de la Universidad de Cádiz en el Puerto de Santa María. 1998: 9-39.

GRAS, M.; ROUILLARD, P.; TEIXIDOR, J. (2000): L'universo fenicio. Einaudi, Turín

HARRISON, R.J. (2004): Symbols and Warriors. Images of the European Bronze Age. Bristol.

HELAS, S.; MARZOLI, D. eds. (2009): Phöenizisches und Punisches Städtewesen., Iberia Archaeologica 13, Mainz am Rhein.

HERZOG, Z. (1992): "Settlement and fortification planning in the Iron Age" en VV.AA. The architecture of the Ancient Israel. From the Prehistoric to the Persian Periods, pp. 231-274.

HUNT, M. A. (1995): "Intervención arqueológica de urgencia en el yacimiento Cerro del Castillo, Aznalcóllar (Sevilla)". Anuario Arqueológico de Andalucía, III, Actividades de Urgencia: 507-512.

HUNT, M. A. (2003): Prehistoric mining and metallurgy in South West Iberian Peninsula. BAR.

JUÁREZ MARTÍN, J. ET ALII (1998): “Estepa tartésica. Excavaciones en el cerro de San Cristóbal". Revista de Arqueología 208: 16-23.

KRISTIANSEN, K. (1998): Europe before history. Cambridge University Press.

LOPEZ CASTRO, J. L. (2000): "Formas de intercambio de los fenicios occidentales en época arcaica" en Fernández Uriel, P. ; Wagner, C. G. y López Pardo, F. eds., Intercambio y Comercio Preclásico en el Mediterráneo. Actas del I encuentro del CEFYP, Madrid: 123-131.

MAIA, Ma . G. (2000): “Tavira fenicia. O territòrio para occidente do Guadiana, nos inicios do I milenio a.C." en A. González Prats (ed.), Fenicios y Territorio (Actas del II Seminario Internacional sobre Temas Fenicios): 121-150. Instituto Alicantino de Cultura "Juan Gil Albert"Generalitat Valenciana.

MARZOLI, D.; GONZÁLEZ WAGNER, C.; SUAREZ, J.; MIELKE, D.P.; LÓPEZ PARDO, F.; LEÓN, C.; THIEMEYER, H.; TORRES, M. (2009): "Vorbericht zu den Deutsch-Spanischen Ausgrabungen in der EndBronzezeitlichen siedlung von Los Castillejos de Alcorrín, Manilva (Prov. Málaga) 2006 und 2007." Madrider Mitteilungen, 50: 118-148. 
MARZOLI, D.; LÓPEZ PARDO, F.; SUAREZ, J.; GONZÁLEZ WAGNER, C.; MIELKE, D.P.; LEÓN, C.; RUIZ CABRERO, L.; THIEMEYER, H.; TORRES, M. (2010): "Los inicios del urbanismo en las sociedades autóctonas localizadas en el entorno del estrecho de Gibraltar: Investigaciones en Los Castillejos de Alcorrín y su territorio (Manilva, Málaga.”, Menga. Revista de Prehistoria de Andalucía, 1: 153-183.

MEDEROS MARTÍN, A. (2005): “La cronología fenicia: Entre el Mediterráneo Oriental y el Occidental." en S. Celestino y J. Jiménez Ávila, eds., El período Orientalizante: 305-346.

MORET, P. (1996): Las fortifications ibèriques. De la fin de l’̂̀ge du Bronze à la conqueste romaine. Collection de la Casa de Velàzquez 56.

MORET, P. (2001): « Del buen uso de las murallas ibéricas ».Gladius, XXI : 137-144.

OLIVER FOIX, A. ed. (2006): Arquitectura defensiva. La protección de la población y del território en época ibérica., Castellón de la Plana.

PARREIRA, R. (1971-75): “O povoado da Idade do Bronze do Outerio do Circo (Beringel, Beja)", Arquivo de Beja, 28-32: 31-45.

PARREIRA, R. (1998): “As arquitecturas como factor de construção da paisagem na Idade do Bronze do Alentejo interior en Oliveira, S. (ed.), Existe uma Idade do Bronze Atlântico?. Trabalhos de Arqueologia 10: 267-273.

PAÇO, A. y VENTURA, J. (1961): "Castelo do Giraldo ( vora): trabalhos de 1960. Revista de Guimarães, 71: 27-49.

PÉREZ MACÍAS, J. A. (1995): “Poblados, centros mineros y actividades metalúrgicas en el Cinturón Ibérico de Piritas durante el Bronce Final" en Actas del Congreso Conmemorativo del V Symposium Internacional de Prehistoria Peninsular: Tartessos 25 años después (19681993). Jerez de la Frontera: 417-447.

PÉREZ MACÍAS, J. A. (1991): “El yacimiento de Bronce Final de los Riscos del Castillo (Cabezas Rubias, Huelva)". Cuadernos del Suroeste, 3: 89113.

PÉREZ MACÍAS, J. A.; CAMPOS CARRASCO, J. M. y GÓMEZ TOSCANO, F. (2000): "Niebla, de oppidum a madina". Anales de Arqueología Cordobesa, 11: 91-122.

PRADOS MARTÍNEZ, F.; BLANQUEZ, J.J. (2007): "Las fortificaciones coloniales en la Península Ibérica: De los modelos orientales a los sistemas púnico-helenísticos.” en L. Berrocal-Rangel y P.
Moret, eds., Paisajes fortificados de la Edad del Hierro: 57-74, Madrid.

QUESADA, F. (2001): “En torno al análisis táctico de las fortificaciones ibéricas. Algunos puntos de vista alternativos". Gladius, XXI: 145-154.

RAKOB, F (1998): “Cartago. La topografía de la ciudad púnica: Nuevas investigaciones" en Cuadernos de arqueología mediterránea, Cartago Fenicio-Púnica: Las excavaciones alemanas en Cartago 1975-1997), nº 4 1998: 14-36

RIVA, C.; VELLA, N.C. eds. (2006): Debating Orientalization. Multidisciplinary Approaches to Change in the Ancient Mediterranean. Mon. in Mediterranean Archaeology, 10, LondonOakville.

RODRÍGUEZ DÍAZ, A. y ENRIQUEZ NAVASCUÈS, J. J. (2001) Extremadura tartésica. Arqueología de un proceso periférico. Bellaterra Arqueología. Barcelona.

ROWLANDS, M. (1987): “Centre and Periphery: a review of a concept" en M. Rowlands, M. Larsen y K. Kristiansen, Centre and Periphery in the Ancient World. Cambridge University Press.

RUIZ GÁLVEZ, M.L. (1998): La Europa atlántica en la Edad del Bronce. Un viaje a las raíces de la Europa occidental. Crítica Arqueología, Barcelona.

RUIZ MATA, D. (2000): "Fenicios e indígenas en Andalucía Occidental. Tartessos como paradigma" en D. Ruiz Mata (ed.), Fenicios e indígenas en el Mediterráneo y Occidente: modelos e interacción. Actas de los Encuentros de Primavera de la Universidad de Cádiz en el Puerto de Santa María. 1998: 9-39.

RUIZ MATA, D. (2001): “Arquitectura y urbanismo en la ciudad protohistórica del Castillo de Doña Blanca (El Puerto de Santa María, Cádiz)” en D. Ruiz Mata y S. Celestino Pérez (eds.), Arquitectura oriental y orientalizante en la Península Ibérica. Centro de Estudios del Próximo Oriente: 261-274.

RUIZ MATA, D.; NIVEAU DEVILLEDARY, A. M M $^{\mathrm{a}}$ VALLEJO SÁNCHEZ, J. I. (1998): "La ciudad tartesico-turdetana" en Aranegui, C. (ed.), Actas del Congreso internacional: Los iberos, príncipes de occidente, las estructuras de poder en la sociedad ibérica. Saguntum extra 1: 65-82.

RUIZ MATA, D. y CELESTINO PÉREZ, S. (eds.) (2001): Arquitectura oriental y orientalizante en la Península Ibérica. Instituto de Historia del CSIC. Mérida. 
RUIZ, A.; MOLINOS, M. y CHOCLÁN, C. (1991): "Fortificaciones ibéricas en la Alta Andalucía" en Fortificacions. La problemática de l'ibèric ple (segles IV-III a. C.), Manresa: 109-126.

RUIZ, A., MOLINOS, M. y RISQUEZ, C. (1998): "Paisaje y territorio mundo: dos dimensiones de una misma teoría arqueológica". Arqueología Espacial, 19-20: 21-32.

SALA SELLÉS, F. y LÓPEZ PRECIOSO, F. (1995): "Los Almadenes (Hellín, Albacete) un poblado orientalizante en la desembocadura del río Mundo" en Actas del IV Congreso Internacional de Estudios Fenicios y Púnicos: Cádiz, 2 al 6 de octubre de 1995, Vol. 4, 2000: 1885-1894.

SERRA, M. y PORFÍRIO, E. (en prensa): “O povoado do Bronze Final do Outeiro do Circo (Mombeja, Beja). Balanço de 2 anos de investigação". $I I^{\circ}$ Encontro de Jovens Investigadores, Universidade do Porto, CEAUCP/CAM, 9, 10 de Abril de 2010.

SERRANO, L.; LLOMPART, J.; y GONZÁLEZ DE CANALES, F. (2004): El emporio fenicio colonial de Huelva (ca. 900-770 a.C.). Biblioteca Nueva.

SILVA; A. C.; L. BERROCAL-RANGEL; V. RODERO OLIVARES (2012) : "Le rempart vitrifié du Castro dos Ratinhos (Moura, Portugal) et la question de la vitrification dans les fortifications protohistoriques dans la Peninsule Ibérique. », en S. Krausz y A. Colin, eds., Archéologie de l'Âge du Fer en Europe., Institut Ausonius, Bordeaux, en prensa.

SOARES, A. MONGE (1986): “O povoado do Passo Alto. Escavações de 1984”. Arquivo de Beja, 3: 89-99.

SOARES, A. MONGE (1996): "Povoado da Misericòrdia (margem esquerda do Guadiana, Serpa). Ocupações humanas e vestigios metalúrgicos". Vipasca, 5: 103-116.
SOARES, A. MONGE (2003): "O Passo Alto: uma fortificaçao do Bronze Final do Sudoeste" Revista Portuguesa de Arqueologia 6. 293-312.

SOARES, A. MONGE (2007): "Cavalhos-de-frisa e muralhas vitrificadas no Bronze Final do Sudoeste. Paralelos europeus.", Estudos arqueológicos de Oeiras. A Arqueología protuguesa e o espaço europeu. Balanços e perspectivas, 15: 155-182.

SOARES, A. MONGE; MARTINS, J.M.M. (2010): "A cronologia absoluta para o Castro dos Ratinhos. Data de Radiocarbono.", en L. Berrocal-Rangel y A.C. Silva, O Castro dos Ratinhos: 409-414, Lisboa.

VAZQUEZ PAZ, J. (2001): “Carmona, plaza fuerte del Bajo Guadalquivir" en Congreso Internacional: Fortificaciones en el entorno del Bajo Guadalquivir. Alcalá de Guadaira: 179-183.

VIVES-FERRANDIS SÁNCHEZ, J. (2005): Negociando encuentros. Situaciones coloniales $e$ intercambios en la costa oriental de la Península ibérica (ss. VIII-VI a.C.)., Cuadernos Arqueología Mediterránea, 12, Barcelona.

WAGNER, C. y ALVAR, J. (1989): "Fenicios en Occidente: la colonización agrícola, en RSTF, 17: 61-102.

WAGNER, C. (1995): "Fenicios y autóctonos en Tartessos. Consideraciones sobre las relaciones coloniales y la dinámica de cambio en el Suroeste de la Península Ibérica". Trabajos de Prehistoria, 52: 109-126.

WAGNER, C. (2005): "Fenicios en extremo occidente: conflicto y violencia en el contexto colonial arcaico", en Revista Portuguesa de Arqueología, 8:2, 177-192. 
